\title{
INCOME INEQUALITY AS A RESULT \\ OF THE DIFFERENT SECTORAL STRUCTURE AT THE LOCAL LEVEL
}

\author{
Monika Daňová ${ }^{1}$ \\ Ivana Kravčáková Vozárová ${ }^{2}$ \\ Roman Vavrek ${ }^{3}$
}

Received: November 15, 2019 / Revised: January 3, 2020 / Accepted: February 14, 2020

(C) Association of Economists and Managers of the Balkans, 2020

\begin{abstract}
Long-term income differences between regions are undesirable from an economic and social point of view. Nevertheless, they are a long-term phenomenon in many countries. Although comparing the countries with each other, the situation appears to be similar. The assumption of reducing the differences in the size of household income is to identify objectively the determinants of wages. According to published opinions, the difference in labor income is due to the different value of the marginal product of labor and thus the resulting wage. Alternative views associate wage size with market factors - the labor market situation, the overall wealth of households, the location of the region, the increase or dampening of the economic activity of the system. The aim of this paper is to analyze and quantify the influence of different branch structure on the regional nominal wage. The model change estimates the possible change in the regional wage caused by the change in the representation of individual sectors in the regions of Slovakia. The factors considered for regional disparities are the representation of the manufacturing sector, sectoral labor productivity and labor market participation.
\end{abstract}

Keywords: Income, Inequality, Regional Disparities. Sectoral Structure, Slovak Republic.

\section{JEL Classification $015 \bullet$ P44}

This paper was presented at the Third International Scientific Conference on IT, Tourism, Economics, Management and Agriculture - ITEMA 2019 - October 24, Bratislava, Slovakia, www.itema-conference.com

Monika Daňová

monika.danova@unipo.sk

1 University of Prešov in Prešov, Faculty of Management, Department of Economics and Economy, Konštantínova 16, 08001 Prešov, Slovakia

2 University of Prešov in Prešov, Faculty of Management, Department of Economics and Economy, Konštantínova 16, 08001 Prešov, Slovakia

3 Technical University of Liberec, Faculty of Economics, Department of Informatics, Voroněžská 13, 46001 Liberec 1, Czech Republic 


\section{INTRODUCTION}

Income inequality has an economic and social dimension. Low incomes reduce the purchasing power of households and the economic power of other economic entities. This reduces the ability of business entities to generate capital over a longer period of time, weakens the region's economic performance and jeopardizes the ability of these regions to develop independently. In order to prevent such a situation, the state also has an economic interest in addressing the problem of income disparities. This means applying tools in national economic policy to eliminate inequalities in income between regions. The solution requires to know the causes of this state, i.e. identify the factor (group of factors) that has a decisive influence on the size of work income.

The issue has long been of interest. The published work shows the diversity of opinions on determinants of wages and on determinants of regional differences. The authors apply the approaches of classical, neoclassical and contemporary wage theories. Suhányi et al. (2016), Pasquazzi and Zenga (2018), German-Soto and Brock (2020) confirmed the dependence of labor price on the size of supply and demand in the labor market. Chua et al. (2017) found a positive long-term relationship between labor productivity and wages by examining the relationship between labor productivity, wages, working time, foreign direct investment, human capital and inflation. Gali (1999), Feldstein (2008), Salvatore (2008), Zenou (2011), Xu et al. (2015) note the significant impact of frontier productivity on labor costs in the short run. The impact of the sectoral structure on wages was monitored by Rajč́ková a Švecová (2009). On the basis of the identified regional differences, it notes the link between economic growth, sectoral structure and the social situation. Similarly, Giacinto a Nuzzo (2005), Adamczyk-Łojewska (2013), Amara and Thabet (2019) found that differences between regions are mainly due to differences in the level of labor productivity in individual regions, to a lesser extent in sectoral structure. International comparisons conducted by Esteban (2000), Ezcura et al. (2007), Policardo et al. (2019), Adamczyk-Łojewka (2013) at different times showed a reduction in labor productivity gaps while widening regional and sectoral disparities at national level.

The findings of significant differences in both sectoral labor productivity and sectoral employment indicate the concurrent, complex impact of several factors, the limited impact of different sectoral structures on spatial diversity of labor productivity and wages. This is in contrast to the expectation of differences in labor productivity across sectors, not between regions. The observed situation may therefore be due to the labor market situation or other endogenous factors, e.g. factors determining the competitive advantage (Esteban 2000).

In the labor market, the value created by labor is the subject of exchange. The payment for this value is the wage paid to the worker. From the company's point of view, the benefit gained from the employment of another employee is the additional product that this employee creates. The damage is represented by the cost of employment of that worker, that is, his wage. Therefore, in order to maximize profits, a firm will only require additional factors of production if the marginal product of the production factor does not fall to the level of the actual price of that factor.

The value of the marginal product differs in different productions (sectors). This means that labor costs also differ in different productions (industries). In sectors with higher labor productivity, wages will be higher than in less productive sectors (Amara a Thabet 2019; King 2019). Increasing labor productivity will increase wages. However, this effect is only short-lived (Gali 1999, Feldstein 2008, Salvatore 2008, Zenou 2011, Xu et al. 2015). A longer-term higher wage level in the higher productivity sector may not be sustainable, as the workforce from low-wage sectors will 
migrate to more attractive wage sectors. Thus, the mechanism for determining wages solely by the value of the marginal product of labor ceases to apply.

Bruce (2002), Huizinga a Broer (2004) consider wages to be the result of a complex effect of several factors (Esteban 2000). In particular, the demand for production factors is derived from the demand for products in which this labor force is involved. The decline in demand for products will reduce their market price, and will also cause wages to decrease without changing labor productivity. Another example is the situation that results from an increase in labor productivity and a consequent increase in production in the sector. Increased supply will reduce prices in the sector, resulting in a decrease in incomes per worker, secondary as well as a decline in wages. The logical conclusion is that there can be only a partial, time-limited link between sectoral labor productivity and wages (Hannan a Kleinsorge 2018). At the same time, other endogenous factors are also affecting the price of labor, for example, there may be a constant downward pressure on agricultural production prices that hinders wage growth in agriculture despite productivity increases.

It can therefore be assumed that labor market pricing is a multi-stage process that partially respects two principles:

1 Value-based principle: based on a comparison of labor cost with the contribution of labor to product value. this means that higher wages will be in productions with higher labor productivity. Logically, in regions with a high proportion of high-productivity sectors, the average wage will be higher than in regions with a high proportion of low-productive sectors.

2. Market principle: based on the correction of the price of labor formed on the value principle due to the influence of several endogenous and exogenous factors.

The first step in the wage pricing process is to determine the price of labor on the basis of the value of the labor contribution to the value of the product.

In this paper we analyze whether the reason for the income differences between the regions of Slovakia results from the different sectoral structure of the economies of these regions, or the differences can be considered as a result of the influence of other determinants of wage size. The material is logically divided into three parts. The introduction is based on the research of published findings on wage determinants. In the analytical part, in order to answer the question of what are the causes of regional differences in the average wage, we use regional and sectoral approach. The impact of the branch structure on average wages is monitored on the basis of their differences in the regions of Slovakia at the NUTSIII level. The last part presents the main findings.

\section{METHODOLOGY}

Differences between regions are tested by a non-parametric set of methods with the intention of identifying differences in range and mean. The impact of the sectoral structure on the average wage in the regions is analyzed by means of a multiple regression model. The dependent variable is the nominal wage of an employee in the region and independent variables are the regional shares of sectors in regional gross value added. Generally, it is possible to describe the model used for individual regions as follows:

$$
\begin{aligned}
& \text { salary }=r_{A} \times A+r_{(B-E)} \times(B-E)+r_{F} \times F+r_{(G-I)} \times(G-I)+r_{J} \times J+r_{K} \times K+r_{L} \times L+ \\
& r_{(M-N)} \times(M-N)+r_{(O-Q)} \times(O-Q)+r_{(R-U)} \times(R-U)
\end{aligned}
$$


where:

salary - measured value of the dependent variable,

$A-U$ - independent variables, shares of sector in GVA of region,

$r_{-i j}$ - regressors of the industry's impact on regional wages.

The informative ability is verified by the coefficient of determination:

$$
R^{2}=\frac{\sum_{i=1}^{n}\left(y_{i}-\hat{y}_{i}\right)^{2}}{\sum_{i=1}^{n}\left(y_{i}-\bar{y}_{i}\right)^{2}}
$$

where:

$y_{i}$ - measured value of dependent variable,

$\hat{y}_{i}$ - estimated value of the dependent variable,

$\bar{y}_{i}$ - average value of dependent variable.

The classification criterion describing the sectoral structure was the valid classification of sectors according to the NACE nomenclature. The criterion describing the territorial structure was the current classification of territorial units at the NUTS 3 level (Table 1). In order to express the structure of the economy of the region, the shares of sectors in the total regional gross value added were calculated.

Table 1. Territorial units of Slovakia at NUTS 3 level

\begin{tabular}{lll|lll}
\hline Code & Name NUTS3 & Abbreviation & Code & Name NUTS3 & Abbreviation \\
\hline SK010 & Bratislava region & SK-BL & SK031 & Žilina region & SK-ZI \\
\hline SK021 & Trnava region & SK-TA & SK032 & Banská Bystrica region & SK-BC \\
\hline SK022 & Trenčín region & SK-TC & SK041 & Prešov region & SK-PV \\
\hline SK023 & Nitra region & SK-NI & SK042 & Košice region & SK-KI \\
\hline
\end{tabular}

The data sources were DATAcube databases and STATdat of the Statistical Office of the Slovak Republic. Data were analyzed for the period 2002 - 2017. All analyzes were processed in MS-Excel and statistical programs Statgraphics XVIII and Statistica 13.4.

\section{RESULTS AND DISCUSSION}

In the first step of the analysis we focus on demonstrating differences in average wages in individual regions of the SR, the occurrence of which is long-term and unchangeable. For the whole reporting period, i.e. years 2002 - 2017, we can observe the highest measured values in the Bratislava self-governing region (SK-BL). In the Bratislava region, the average and median value was higher than EUR 1000, and the second was the Trnava Region (SK-TA), which lags more than EUR 300 ( $x_{S K-T A}=770.50$ EUR). In terms of regions, the lowest rating of employees was found in the Prešov region $\left(\overline{x_{S K-P V}}=637.37\right.$ EUR).

The above structure caused the rejection of the null hypothesis of the Kruskal-Wallis test and thus the confirmation of differences between individual regions $(\mathrm{Q}=31.478 ; \mathrm{p}<0.05)$. The reason can be found in highly above-average values in SK-BL, which statistically significantly differed from all self-governing regions with the exception of Košice region (SK-KI).

The significant difference in wages in SK-BL and SK-KI is obviously influenced by the location of two major metropolises (Bratislava - the capital, Košice - the second largest seat in the SR in terms of population concentration and economic activities). According to statistics, it is a com- 
mon phenomenon that in regions where is a capital seat or a large settlement, the wage is usually up to $130 \%$ of the national average.

It is interesting to note that these differences are long-term, with the average wage dispersion in regions being constant and equal $(\mathrm{LE}=0.539 ; \mathrm{p}=0.803)$, which is also evident from the graphical comparison (Figure 1).

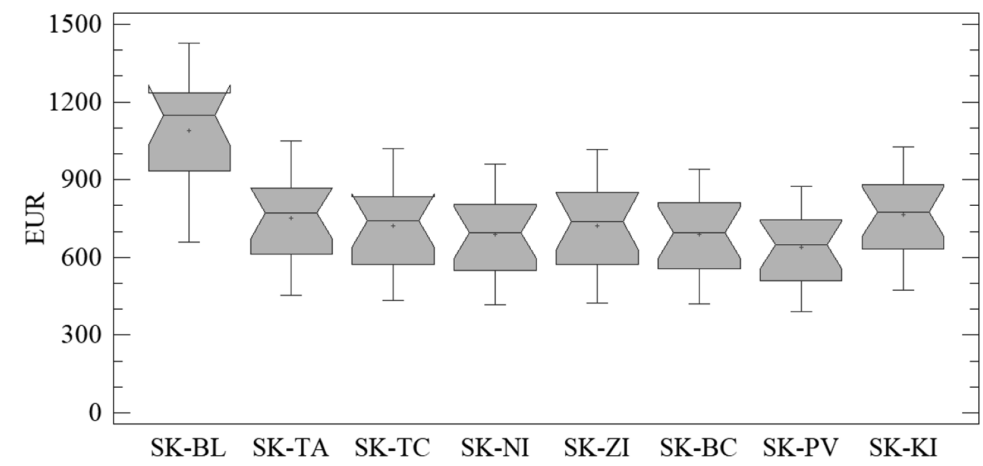

Figure 1. Comparison of the average wage in the regions of Slovakia for the years 2002 - 2017 (in EUR)

It can be concluded that changes in time, respectively, the size and nature of the year-on-year change in the average wage in individual regions can be observed mainly until 2012. Later, the development in individual regions is comparable and shows the same trend. Based on this fact, i.e. there is no reason to assume a decrease in the identified regional differences in the average wage.

It must be assumed that the resulting differences are due to other endogenous factors. Given the diverse structure of the sectors, respectively economic activity, which is dominant in individual regions, it is appropriate to consider as such a factor of different structure of sectors, especially different shares of high and low productive sectors in the creation of regional gross value added. For the whole monitored period 2002 - 2017, a stable structure of the share of sectors in the creation of regional added value was found in all regions (Figure 2).

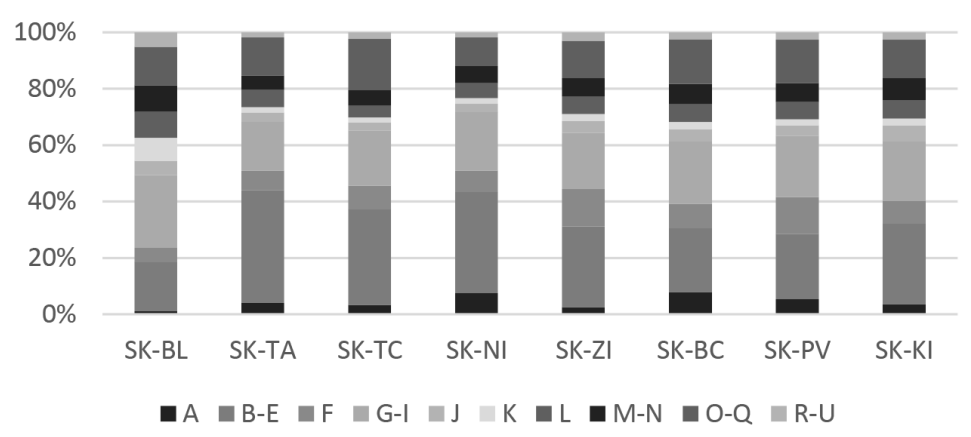

Figure 2. Share of sectors in gross value-added creation in individual regions of the SR

Comparison between regions showed:

- the specific position of SK-BL with a high representation of the most productive and thus above-average sectors and a low share of agriculture and industry in the region compared to other regions, 
- among all regions, the highest share of agriculture in the creation of gross value added in SK-BC, while at the same time was showed a low share of industries, including construction in this region,

- low share of agriculture in the creation of gross value added in SK-BC, and at the same time a high share of industries in SK-TC and SK-ZI, similarity of regional structure of economic activities in SK-KI to national structure of economic activities.

The aim of further analysis was to determine the significance of the impact of the sectoral structure on the nominal wage. This was analyzed by multiple regression individually for each assessed region. The models developed shall quantify the impact of the sector's contribution to nominal wage as shown in Table 2 .

Table 2. Quantification of the impact of the sector on the average wage according to NUTS 3

\begin{tabular}{llrll}
\hline & \multicolumn{1}{c}{ NUTS 3 } & $\mathbf{R}^{\mathbf{2}}$ & \multicolumn{1}{c}{ Positive impact } & \multicolumn{1}{c}{ Negative impact } \\
\hline SK-BL & Bratislava region & 0.9989 & B-E; G-I; J, M-N; R-U & A; F; K; L; O-Q \\
SK-TA & Trnava region & 0.9977 & B-E, F, J, K, O-Q & A, G-I, J, M-N, R-U \\
SK-TC & Trenčín region & 0.9987 & A, B-E, F, G-I, K, M-N, O-Q & J, L, R-U \\
SK-NI & Nitra region & 0.9924 & B-E, F, K, M-N, O-Q, R-U & A, G-I, J, L \\
SK-ZI & Žilina region & 0.9995 & B-E, F, J, K, M-N, O-Q & A, G-I, L, R-U \\
SK-BC & Banská Bystrica region & 0.9992 & A, B-E, F, M-N, R-U & G-I, J, K, L, O-Q \\
SK-PV & Prešov region & 0.9990 & B-E, F, G-I, L, M-N, R-U & A, J, K, O-Q \\
SK-KI & Košice region & 0.9996 & A, J, K, M-N & B-E, F, L, O-Q, R-U \\
\hline
\end{tabular}

Almost perfect predicative value of all models, verified by the coefficient of determination, allows the obtained results to be considered as sufficiently representative of the variability of the dependent variable, i.e. average gross nominal wage by using a set of independent variables (shares of individual sectors in regional gross value added). This makes it possible to identify the sectors that have a negative (positive) impact on wages in most instances, and to specify for each region sectors with a negative (positive) impact on the wage in the region.

Based on these findings, we can conclude that:

1. Sectors which had a positive impact on wages include industry (B-E), construction (F) and activities classified in the NACE group (M-N).

2. Agriculture (A) and real estate activities (L) had the most negative impact on wages. Trade, transport, accommodation and food services (G-I), information and communication sector $(\mathrm{J})$, financial and insurance activities $(\mathrm{K})$, public administration, education and health sector $(\mathrm{O}-\mathrm{Q})$ and arts, recreation and other activities (R-U) had also often the negative-impact on wages.

3. The sector's wage impact in the region shows signs of similarity only when determining the nature of the impact (positive, negative). The intensity of the sector's influence depends on the size of the sector's share of the structure of economic activities, as well as on the proportions of the share of the entire set of sectors in the region.

\section{CONCLUSION}

This document examined spatial variability of wages in regions of Slovakia. Our approach was based on the use of multiple regression models, which made it possible to quantify the sources of spatial heterogeneity of wages often reported in the current literature. The first finding is the spatial diversity of wages caused by the localization of a metropolis or a significant economic settlement in 
the region. Also, the comparability of wage trends and the resulting relative stability in the size of wage differences between regions. Another finding is the positive impact of sectoral diversification: in individual regions, the negative impact of one of the sectors on the average nominal monthly wage was weakened in each region by the positive effect of also under-represented, but wage-favorable sectors. In regions with a low share of low-wage sectors (e.g. agriculture in SK-BL, SK-TC, SK-ZI), the intensity of impact is weakened by the high proportion of better-valued wage sectors (in the mentioned SK-BL, SK-TC and SK-ZI mainly sectors in the B-E group or service in the J-M group). The findings of the analyzes also confirmed the effect of labor market supply and demand on the wage level and the weakened relationship between labor productivity and wages.

\section{ACKNOWLEDGMENT}

This research was supported by the Scientific Grant Agency of the Ministry of Education, Science, Research and Sport of the Slovak Republic and the Slovak Academy of Sciences under grant VEGA 1/0082/19 and by the Cultural and Educational Grant Agency of the Ministry of Education, Science, Research and Sport of the Slovak Republic and the Slovak Academy of Sciences under grant KEGA 038PU-4/2018. This work was also supported by the OP VVV - International Mobilities of Researchers at the Tul [CZ.02.2.69/0.0/0.0/16_027/0008493].

\section{REFERENCES}

Adamczyk-Łojewska, G. (2013). Work Productivity as an Economic Growth and Prosperity Factor in Poland from 2004-2010. Studia i Materialy Polskiego Stowarzyszenia Zarzadzania Wiedza, (67), 38-53.

Amara, M. \& Thabet, K. (2019). Firm and regional factors of productivity: a multilevel analysis of Tunisian manufacturing. Annals of Regional Science, 63(1), 25-51.

Bruce C. (2002). The Connection between Labour Productivity and Wages. Economica LTD, The Expert Witness, 7(2), 68-74.

Esteban, J. (2000). Regional convergence in Europe and the industry mix: a shift-share analysis. Regional Science and Urban Economics, 30(3), 353-364.

Ezcurra, R., Pascual, P. \& Rapún, M. (2007). Spatial Inequality in Productivity in the European Union: Sectoral and Regional Factors. International Regional Science Review, 30(4), 384-407.

Feldstein, M. (2008). Did wages reflect growth in productivity? Journal of Policy Modeling, 30(4), 591-594.

Gali, J. (1999). Technology, employment and the business cycle: Do technology shocks explain aggregate fluctuations? America economic review, 89(1), 249-271.

German-Soto, V. \& Brock, G. (2020). Are Mexican manufacturing workers underpaid? Some quarterly time series evidence. Journal of Developing Areas, 54(2), 75-93

Di Giacinto, V. \& Nuzzo. G. (2005). Explaining Labour Productivity Differentials on Italian Regions, Bank of Italy. Economic Research Unit, 1-31.

Hannan, M.T. \& Kleinsorge, P.L. et al. (2018). Wage and salary. Encyclopedia Britannica. https:// www.britannica.com/topic/wage

Huizinga F. \& Broer, P. (2004). Wage moderation and labour productivity. Netherlands Bureau for Economic Policy Analysis, series CPB Discussion Papers, nr.28.

Chua, L.Y., Low, S.L., Tan, K.W., Tiang, Yi M. \& Yeap, X.Y. (2017). The Determinants of Labor Productivity in United Kingdom. Final Year Project, UTAR.

King, J.E. (2019). Some obstacles to wage-led growth. Review of Keynesian Economics, 7(3), 308-320. Pasquazzi, L. \& Zenga, M. (2018). Components of Gini, Bonferroni, and Zenga Inequality Indexes for EU Income Data. Journal of Official Statistics, 34(1), 149-180. 
Policardo, L., Punzo, L.F. \& Carrera, E.J.S. (2019). On the wage-productivity causal relationship. Empirical Economics, 57(1), 329-343.

Rajčáková, E. \& Švecová, A. (2009). Regionálne disparity na Slovensku. Goographia Cassoviensis, (3) $2,142-149$.

Salvatore, D. (2008). Growth, productivity and compensation in the United States and in the other G-7 countries. Journal of Policy Modeling, 30(4), 627-631.

Suhányi, L., Suhányiová, A., Horváthová, J. \& Mokrišová, M. (2016). Research in wages in selected countries of the European Union and in regions of Slovakia. In International Multidisciplinary Scientific Conference on Social Sciences and Arts SGEM 2016, Albena, (pp.521-528). Bulgaria: Curran Associates, Inc.

Xu, Z., Chen, Y. \& Li, M. (2015). Are Chinese Workers Paid the Correct Wages? Measuring Wage Underpayment in the Chinese Industrial Sector, 2005-2010. Review of Radical Political Economics, 47(3), 446-459.

Zenou, Y. (2011). Rural-urban migration and unemployment: Theory and policy implications. Journal of Regional Science, 51(1), 65-82. 